\title{
Defining the nodal equivalent parameters using synchrophasor measurements
}

\author{
Alexander Berdin, Dmitriy Bliznyuk and Pavel Kovalenko \\ Automated Electrical Systems Department, Ural Federal University named after the first President of Russia B.N. Yeltsin. 19 Mira St., \\ Yekaterinburg, Russia
}

\begin{abstract}
The method for defining the nodal equivalent parameters of grid elements based on synchrophasor measure-ments during transients in a power system is proposed. It allows to define the topology and parameters of nodal equivalents and makes it possible to implement adaptive models for problems of power system control.
\end{abstract}

\section{1 introduction}

The rapid development and steadily widening introduction of synchrophasor measurements technology (or just synchrophasors) in power systems all over the world enable new possibilities to improve the quality of primary equipment models involved in power system control applications. This is much more important taking into account the growing complexity of power systems and the impossibility to replace them in all fields of humanity existence and sustainable socioeconomic development.

Conventional approach to emergency control implies utilizing detailed models, characterized by a large amount of parameters [1]. At that, the problem of their definition is complicated due to various factors, including the absence of factory reference values, the complexity of obtaining the parameters of equipment supplied from other countries, change of the parameters over time etc. Hence, utilizing those models can potentially lead to obtaining the results significantly different from the real object in operation and applying the improper control actions to the system.

To date there are numerous projects carried out on developing the adaptive models for power systems primary equipment with the parameters being defined based on the synchrophasor measurements. Specifically, the methodology for defining the instantaneous power system performance parameters was developed [2], allowing to significantly improve the accuracy of the performance parameters calculation during electromechanical transients, including the changes over periods shorter than the industrial frequency; the possibility of defining the inertia constant of a power generating unit [3] and its damping capabilities [4], constituting the most valuable part of a synchronous machine adaptive model were investigated in detail. The next necessary stage of this research is evaluating the mutual influence of synchronous machines in the same power system and rectifying the parameters of their models by taking this influence into account. In order to address this challenge the technique for defining the parameters of power transmission network nodal equivalents based on synchrophasor measurements obtained from WAMS.

The concept of forming and utilizing the nodal equivalents also known as REI-models was proposed by a Romanian scientist P. Dimo back in 1970s [5, 6]. Till present days their parameters have been being defined on the basis of conventional network equivalent transformations and several original techniques. The models were suggested to be employed for solving a wide range of power system problems. Modern progress in measurement technology allows to adapt some of those investigation results for the purpose of building the adaptive models of power system components.

\section{Defining the equivalent topology}

REI-equivalent is a substitution circuit, completely equivalent to the initial network and independent from the conditions of the rest of the system. REI-equivalent includes the nodes, voltage of which are assumed independent (usually generation nodes) as well as the nodes essential for analysis purposes. Then a network fragment can be selected from the resulting equivalent circuit, containing the node under consideration, all nodes, connected to it, and the connection lines. This fragment is referred to as the nodal model, its distinctive feature is that it is radial and allows to analyze the influence on the node under consideration caused by the other network nodes [5].

The conventional approach to the equivalent topology and parameters definition implies that all nodes, not included into the resulting equivalent circuit, are eliminated by means of Gauss technique. This methodology's drawback is that it can lead to significant errors $[7,8]$, since the reference initial data values might 
substantially differ from the actual ones. The issue is made even worse by the consequential essence of Gaussian elimination procedure, that results in errors accumulation.

It is proposed to preserve the Gaussian elimination procedure for defining the electrical network equivalent topology. However, the problem of defining the equivalent model parameters is proposed to be addressed by utilizing the synchrophasor measurements associated with the nodes which are not eliminated collected during transients resulting from random disturbances (the methodology for defining the parameters is presented in the following section).

The widely known Kundur model [9] (Figure 1) is investigated as an example for the proposed methodology validation. The model comprises 4 generating nodes, 2 load nodes and connecting lines. The initial equivalent circuit is shown in Figure 2. The nodal equivalent implies eliminating all nodes except for the generating ones. Hence, the nodes 1, 2, 3, and 4 are preserved while the nodes 7,8 , and 9 are eliminated. The network reduction results are presented in Figure 3.

REI-equivalent, intended for the analysis of a part of the network influence on the node under examination, can be obtained from the complete network equivalent by eliminating the nodes having no connection with the considered one. Equivalents for each of the network nodes are shown in Figure 4.

The equivalent impedances were defined as well during the equivalent calculations. They are to be used as the reference values in order to compare the experiment results.

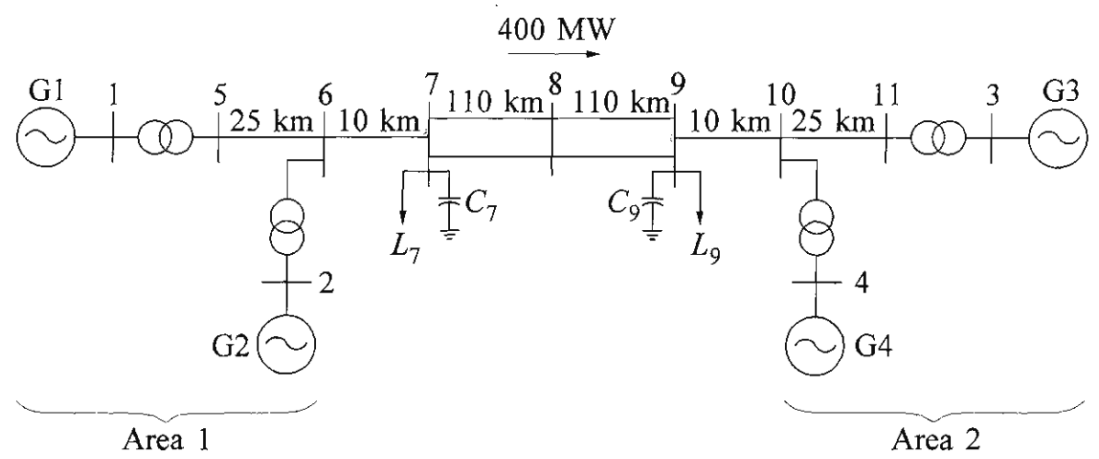

Fig 1. The power system under consideration

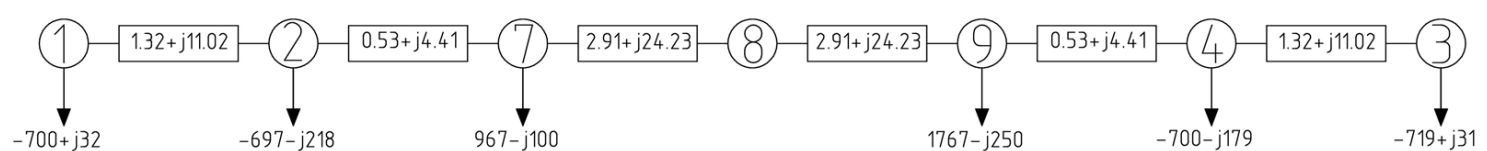

Fig 2. The initial equivalent circuit

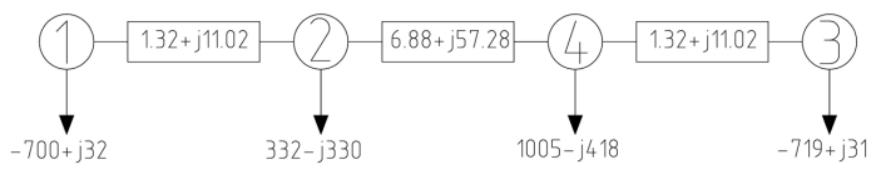

Fig 3. The network equivalent
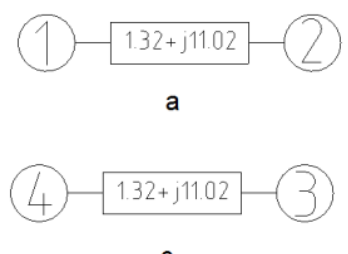

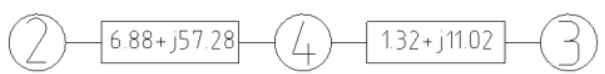

b

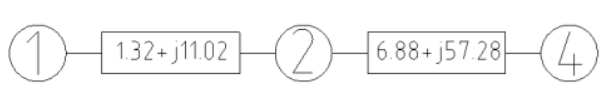

Fig 4. The equivalents associated to each network node ( $\mathrm{a}$ - for node $1, \mathrm{~b}$ - for node $4, \mathrm{c}-$ for node $3, \mathrm{~d}$ - for node 2 ) 


\section{Defining the nodal equivalent parameters}

Nodal equivalent parameters definition is based on the commonly known electrical engineering laws. Apparent power in a line connecting the $i$ and $j$ nodes is defined according to the following expression:

$$
\dot{S}_{i j}=\sqrt{3} \dot{U}_{i} \bar{I}_{i j}
$$

where $\dot{U}_{i}$ is the $i$ node voltage vector,

$\bar{I}_{i j}$ is the line connecting the $i$ and $j$ nodes current complex-conjugate vector.

Hence, the apparent power complex-conjugate corresponding to the same line after substituting the current expression and algebraic transformation can be rewritten as follows:

$$
\bar{S}_{i j}=Y_{i j} U_{i}\left(U_{j}\left(\cos \delta_{i j}+j \sin \delta_{i j}\right)-U_{i}\right)
$$

where $Y_{i j}$ is the conductance of the line connecting the $i$ and $j$ nodes,

$U$ is the corresponding node voltage,

$\delta_{i j}$ is the angle between the $i$ and $j$ nodes.

In $220 \mathrm{kV}$ (and higher) networks, which are primarily the relevant field for current research, the resistance is significantly smaller, then the reactance, and hence can be neglected. Taking this into account, the real part of (2) can be expressed as follows:

$$
I_{P i j}=b_{i j} U_{j} \sin \delta_{i j}
$$

where $I_{P i j}=\frac{P_{i j}}{U_{i}}$, and $P_{i j}$ is the active power flow over the line connecting the $i$ and $j$ nodes;

$b_{i j}=\frac{1}{x_{i j}}$ is the reactive conductance of the line connecting the $i$ and $j$ nodes, and $x_{i j}$ is its impedance.

By totalizing the corresponding currents for every line connecting the $i$ node to the $n j$ nodes connected to it, one can obtain:

$$
I_{P i}=\sum_{j=1}^{n} b_{i j} U_{j} \sin \delta_{i j}
$$

where $I_{P i}=\frac{P_{i}}{U_{i}}$, and $P_{i}$ is the equivalent active power for the $i$ node.

The expression (4) is used for the purpose of defining the parameters of a nodal model for the $i$ node. The unknown is the reactive conductance of the lines, while the rest of the parameters are WAMS-measured. The unknown can be defined by utilizing the multi-parameter model [10] or the least square technique.

The same expression can be obtained for the imaginary part of (2) as well. Therefore, the expression containing reactive power instead of active power is derived. The combined usage of (4) and the same expression with the reactive power for defining the equivalent parameters is to improve the calculations accuracy.

Equivalent nodal active power $P_{i}$ is a vector sum of the considered node generation, its load and part of a network load distributed into the node. For example, the equivalent nodal active power of $332 \mathrm{MW}$ (see Figure 3) for the node 2 of the considered network shown in Figure 2 is the aggregate of the node generation (which is $-700 \mathrm{MW}$ ) and the part of the nodes 7 and 9 loads. At that, the equivalent active power for the node 1 is only its own generation, since the other nodes load is not distributed into the node.

Therefore, each stage of Gaussian elimination must be accompanied by preserving the coefficients reflecting the share of the load distributed from the eliminated nodes to the remaining ones. Thus, when subtracting the equation $x$, corresponding the eliminated node, from the equation $y$, corresponding to another node, the coefficient of this subtraction must be preserved. These coefficients are referred to as the load distribution coefficients $k_{x}^{y}$. They reflect the share of the node $x$ load transferred to the node $y$. the coefficients for the investigated example are the following:

$$
\begin{aligned}
& k_{2}^{7}=0.923 ; k_{2}^{9}=0.077 ; \\
& k_{4}^{7}=0.077 ; k_{4}^{9}=0.923 .
\end{aligned}
$$

Then the equivalent nodal active power can be derived from the node generation measurements by taking into account all loads, distributed into the node through the load distribution coefficients.

\section{Method validation}

\subsection{Steady state simulation}

The general possibility of utilizing the proposed methodology for the nodal equivalents parameters was validated using Kundur's digital model shown in Figure 1. At the first stage a set of steady-state conditions were simulated using RastrWin software.

10 steady-state conditions were simulated with nodes 1,3 , and 4 generation (node 2 is the swing-bus) being varied from $650 \mathrm{MW}$ to $720 \mathrm{MW}$. Based on the obtained results the impedances of the nodal equivalent networks were calculated for each of the 4 generating nodes. There were two calculations performed - with taking resistance into account and without. The results are summarized in Tables 1 and 2 .

Table 1. The results of evaluating the equivalent parameters based on steady-state simulation measurements (with considering resistance)

\begin{tabular}{|c|c|c|c|c|c|c|}
\hline $\begin{array}{c}\text { Consi- } \\
\text { dered } \\
\text { node }\end{array}$ & $\mathbf{X}_{\mathbf{1 2}}$ & $\mathbf{X}_{\mathbf{2 4}}$ & $\mathbf{X}_{\mathbf{3 4}}$ & $\mathbf{R}_{\mathbf{1 2}}$ & $\mathbf{R}_{\mathbf{2 4}}$ & $\mathbf{R}_{\mathbf{3 4}}$ \\
\hline 1 & 10.96 & & & 1.62 & & \\
\hline 2 & 11.40 & 56.17 & & -0.48 & 0.75 & \\
\hline
\end{tabular}




\begin{tabular}{|c|c|c|c|c|c|c|}
\hline 3 & & & 11.02 & & & 1.36 \\
\hline 4 & & 48.90 & 6.00 & & 15.05 & -6.50 \\
\hline Average & 11.18 & 52.54 & 8.51 & 0.57 & 7.90 & -2.57 \\
\hline $\begin{array}{c}\text { Referen } \\
\text { ce }\end{array}$ & $\mathbf{1 1 . 0 2}$ & $\mathbf{5 7 . 2 8}$ & $\mathbf{1 1 . 0 2}$ & $\mathbf{1 . 3 2}$ & $\mathbf{6 . 8 8}$ & $\mathbf{1 . 3 2}$ \\
\hline Error & $1.45 \%$ & $-8.28 \%$ & $-22.78 \%$ & $-56.86 \%$ & $14.84 \%$ & $-294.6 \%$ \\
\hline
\end{tabular}

Table 1 indicates that taking resistance into account renders the calculation results deviation from the reference values quite significant. The reference was obtained by means of Gaussian elimination (see Figure 3). At that, Table 2 shows that in case calculation is performed without taking resistance into account, the results are close to the reference values. Low accuracy of the calculation with taking resistance into account is due to its small value compared to the reactance. Excluding the resistance from the analysis (Table 2) significantly improves the results accuracy. Apparently, in-deep research of this phenomenon requires the detailed investigation of the utilized computational technique.

Table 2. The results of evaluating the equivalent parameters based on steady-state simulation measurements (without considering resistance)

\begin{tabular}{|c|c|c|c|}
\hline Considered node & $\mathbf{X}_{\mathbf{1 2}}$ & $\mathbf{X}_{\mathbf{2 4}}$ & $\mathbf{X}_{\mathbf{3 4}}$ \\
\hline 1 & 11.08 & & \\
\hline 2 & 11.37 & 55.82 & \\
\hline 3 & & & 11.08 \\
\hline 4 & & 62.92 & 11.47 \\
\hline Average & 11.22 & 59.37 & 11.28 \\
\hline Reference & $\mathbf{1 1 . 0 2}$ & $\mathbf{5 7 . 2 8}$ & $\mathbf{1 1 . 0 2}$ \\
\hline Error & $1.86 \%$ & $3.64 \%$ & $2.35 \%$ \\
\hline
\end{tabular}

However, the combination of calculation results for different nodes allows to obtain the calculated values close to the actual ones. The maximum average values deviation of the calculated values from the reference ones amounted for as low as $3.64 \%$ (without considering resistance).

The experiment results prove the applicability of the proposed method for defining the nodal equivalents parameters based on the steady-state measurements. However, the steady-state measurements change insignificantly over short periods of operation, which leads to the results accuracy decrease. Although longer periods can be considered, the power system topology and performance parameters might change. Therefore, applying the proposed method to the analysis based on steady-state measurements requires that one ensures the limits of the equipment parameters deviations and the fact that the power system topology stays the same.

\subsection{Transient simulation}

Actual practice highlights it is preferable to define the equivalents parameters based on transient measurements since it is transients when the measured parameters deviate in a wide range over short period of time. During transients the network topology generally remains the same, while the significant deviations of the measured parameters decrease the influence of measurement errors, which improves the calculation accuracy. The following experiment was conducted in order to validate the proposed method application to the WAMS emergency recordings.

A disturbance was simulated in Kundur model using MATLAB Simulink. The excitation winding of the generator in node 3 was subjected to a $+5 \% 20 \mathrm{~ms}$ voltage impulse. At the same tome the excitation winding of the generator in node 4 was subjected to a $5 \%$ voltage impulse of the same duration. As a result the low-frequency oscillations emerged. Figures 5 and 6 show the simulated WAMS measurements of the active power and voltage in the generation nodes. The nodal equivalent parameters calculation results for all generation nodes are summarized in Table 3.

The results clearly indicate that the simulated WAMS measurements during transients the accuracy of the nodal equivalents parameters calculation proved to be high. The maximum deviation from the value assumed to be the reference, amounted for $4.02 \%$.

Table 3. The results of evaluating the equivalent parameters based on transient (low-frequency oscillations) simulation measurements

\begin{tabular}{|c|c|c|c|}
\hline Considered node & $\mathbf{X}_{\mathbf{1 2}}$ & $\mathbf{X}_{\mathbf{2 4}}$ & $\mathbf{X}_{\mathbf{3 4}}$ \\
\hline 1 & 10.93 & & \\
\hline 2 & 11.57 & 58.29 & \\
\hline 3 & & & 10.92 \\
\hline 4 & & 60.88 & 11.51 \\
\hline Average & 11.25 & 59.58 & 11.22 \\
\hline Reference & $\mathbf{1 1 . 0 2}$ & $\mathbf{5 7 . 2 8}$ & $\mathbf{1 1 . 0 2}$ \\
\hline Error & $2.08 \%$ & $4.02 \%$ & $1.86 \%$ \\
\hline
\end{tabular}




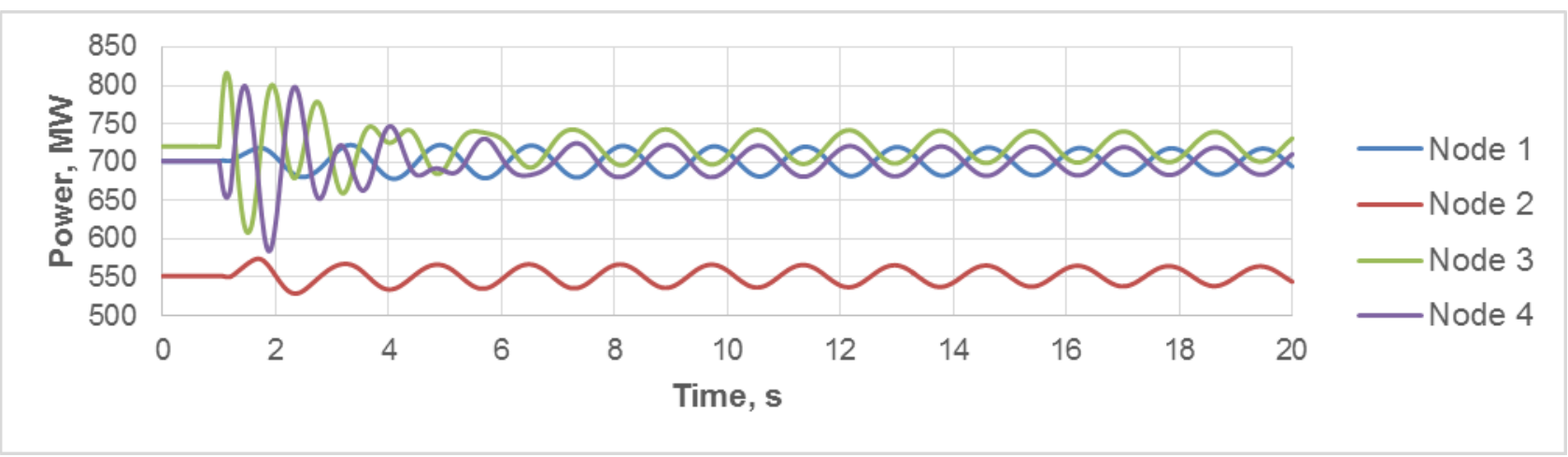

Fig 5. Active power measurements in all nodes of the considered system

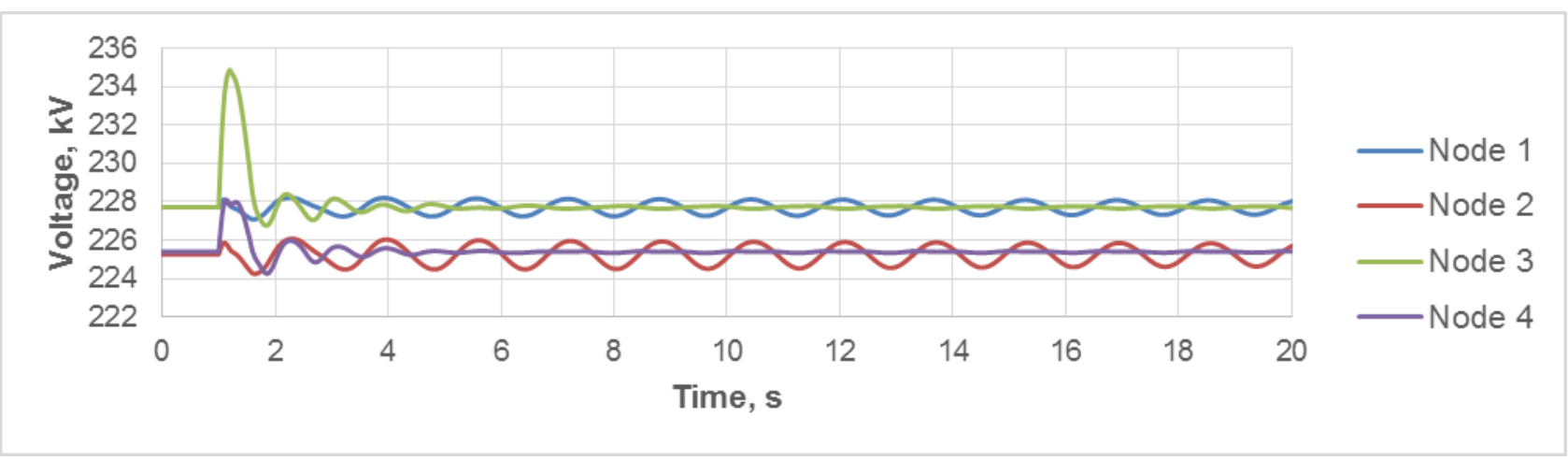

Fig 6. Voltage measurements in all nodes of the considered system

\section{Conclusion}

Current research proposes the method allowing to define the parameters of the network nodal equivalents based on the synchrophasor measurements performed during power system transients. Accumulating the corresponding measurements archive allows to rectify the parameters and define them for different network topologies and operating conditions $[11,12]$.

The method was validated and proved its efficiency using the digital simulation of both steady-state conditions and transients. The defined equivalents parameters values differ from the reference ones by less than $5 \%$, which indicates the proposed method can be applied to defining the nodal equivalents parameters based on the transient measurements.

The developed method plays an important role in assessing the mutual influence of the generators in a power system. The nodal equivalents clearly outline the nodes influencing the considered one and evaluate this influence with the electrical distance between them being calculated.

The next stage of the method development implies its validation using the physical simulation results and actual data collected from the power system objects. The WAMS systems development and improving the synchrophasor observability of the power system suggests a wide range of potential opportunities for implementing the proposed method and employing it in power system dispatch and automatic emergency control.

\section{Acknowledgement}

The work was supported by Act 211 Government of the Russian Federation, contract № 02.A03.21.0006 and the Ministry of Education and Science of Russian Federation (in the framework of state assignment, № 13.1928.2014/K (project № 1928)).

\section{References}

1. G. Shabalin, A. Pazderin, P. Bannykh, E. Balakh. Voltage stability analysis using quadratic objective function taking into account equality constraint // 2016 IEEE International Conference on the Science of Electrical Engineering Proceedings.

2. Berdin A.S., Bliznyuk D.I., Kovalenko P.Y., Egorov A.O., Cherepov A.S. Otsenka mgnovennyh znacheniy parametrov elektricheskogo rezhima $\mathrm{v}$ seti peremennogo toka // Elektricheskie stantsii, \#8 2015.

3. Berdin A.S., Bliznyuk D.I., Gerasimov A.S. Opredelenie ehkvivalentnoj inercionnoj postoyannoj po dannym izmerenij ehlektromehanicheskogo perekhodnogo processa // Izvestiya NTC Edinoj ehnergeticheskoj sistemy \#1 - 2016.

4. Berdin A.S., Bliznyuk D.I., Gerasimov A.S. Ocenka dempfernyh svojstv ehnergobloka s ispolzovaniem ehksperimentalnyh dannyh // Izvestiya NTC Edinoj ehnergeticheskoj sistemy \#2 - 2016. 
5. Dimo P. Uzlovoj analiz ehlektricheskih system. Moscow, 1973.

6. Dimo P. Modeli REI i parametry rezhima. Obyedinennye ehnergosistemy. Moscow, Energoatomizdat - 1987.

7. Kochneva, E.S., Pazderin, A.V., Sukalo, A. Testing equations method for electrical energy measurements systematic errors detection and measurements results adjustment. Journal of Physics: Conference Series 870(1), 2017.

8. Kochneva, E.S., Pazderin, A.V. Improving the method of test equations for the validation of electricity measurements. Power Technology and Engineering 50(6), 2017.

9. Kundur P. Power system stability and control. New York: McGraw-hill, 1994.
10. Bliznyuk D.I., Romanov I.B. Ocenka dostovernosti opredeleniya harakteristik nagruzki po dannym vektornyh izmerenij // Izvestiya NTC Edinoj ehnergeticheskoj sistemy \#2 - 2016.

11. Mukhlynin, N.D., Pazderin, A.V., Sukalo, A. Estimating operating mode parameters in distribution grids with regard to the peculiarities of their development. International Symposium on Industrial Electronics, INDEL 2016.

12. Pazderin, A.V., Pazderin, A.A., Mukhlynin, N.D. Technical and economic model of energy transmission and distribution based on the smart metering technologies. IEEE International Symposium on Industrial Electronics, 2017. 